\title{
1 Movement of lithics by trampling: An 2 experiment in the Madjedbebe sediments, 3 northern Australia
}

\author{
4 Ben Marwick \\ 5 Elspeth Hayes \\ 6 Chris Clarkson \\ 7 Richard Fullagar \\ 8 2017-02-06
}

\begin{abstract}
Understanding post-depositional movement of artefacts is vital to making reliable claims about the formation of archaeological deposits. Human trampling has long been recognised as a contributor to post-depositional artefact displacement. We investigate the degree to which artefact form (shape-and-size) attributes can predict how an artefact is moved by trampling. We use the Zingg classification system to describe artefact form. Our trampling substrate is the recently excavated archaeological deposits from Madjedbebe, northern Australia. Madjedbebe is an important site because it contains early evidence of human activity in Australia. The age of artefacts at Madjedbebe is contentious because of the possibility of artefacts moving due to trampling. We trampled artefacts in Madjedbebe sediments and measured their displacement, as well as modelling the movement of artefacts by computer simulation. Artefact elongation is a significant predictor of horizontal distance moved by trampling, and length, width, thickness and volume are significant predictors of the vertical distance. The explanatory power of these artefact variables is small, indicating that many other factors are also important in determining how an artefact moves during trampling. Our experiment indicates that trampling has not contributed to extensive downward displacement of artefacts at Madjedbebe.
\end{abstract}

\section{Introduction}

23 Claims for the first evidence of human activity, or of new types of activity, at many archaeological sites depend on a close stratigraphic association between culturally modified materials and dated materials. To be confident of these associations we need a robust understanding of how artefacts are displaced from their original locations by post-depositional processes. Examples of problematic vertical separation of artefacts that complicate the interpretation of archaeological deposits have been known for some time. For example, Villa and Courtin (1983) describe conjoinable artefacts up to $1 \mathrm{~m}$ vertically apart and in different deposits. Similarly, Cahen and Moeyersons (1977) report refitting artefacts up with to $1 \mathrm{~m}$ of vertical separation at Gombe Point in Zaire. At FxJj50, Koobi Fora, Kenya, Bunn et al. (1980) report conjoinable pieces up to $50 \mathrm{~cm}$ apart vertically in brief occupation deposits of alluvial sandy silt. At Cave Spring, Tenessee, Hofman (1986) recorded refitting artefacts over 20-40 cm of vertical distance. Richardson (1992) observed a maximum vertical separation of $30 \mathrm{~cm}$ for conjoining artefacts from different excavation units at Kenniff Cave (Queensland, Australia). In this paper we use geological methods to explore clast form and size metrics to identify relationships that might help identify artefacts that have moved due to trampling, and given the form attributes of 
an assemblage, to understand the magnitude of movement that may have occurred in an assemblage.

Our motivation for this study arises from claims of vertical movement of artefacts in debates surrounding the timing of the first human occupation of Sahul, where the archaeological deposits are often sandy and lacking well-defined stratigraphy. Investigations at archaeological sites in northern Australia recovered small numbers of flaked stone artefacts from sandy rockshelter deposits associated with Optically Stimulated Luminescence ages (OSL) 50-60 k BP. The reliability of these associations has been questioned, with critics claiming that post-depositional processes have brought the stone artefacts in association with much older sediments. At Madjedbebe (formerly Malakunanja II), one of Australia's oldest sites, trampling of artefacts has been proposed as a possible cause of dislocation of artefacts down through the deposit into an association with sediments much older than the artefacts (Hiscock, 1990). In this paper we describe a trampling experiment directly relevant to Madjedbebe and other sites with sandy 51 deposits.

Because of the importance of their effect on understanding artefact contexts and associations, trampling experiments are a mainstay of archaeological science (e.g. Driscoll et al., 2015; Eren et al., 2010). For example, Eren et al. (2010) summarised fourteen publications of trampling experiments, all aimed at understanding how human and animal trampling contribute to the spatial displacement of, and damage to, objects commonly found in archaeological sites. The aim of our experiment was to understand how artefacts move in a sandy deposit when trampled by walking. Specifically, we explored the relationship between artefact form parameters and the distance they were moved by trampling. We follow Eren et al. (2010) in focusing on short-term trampling events, and by recording the position, orientation and inclination of the artefacts

61 between each trampling event.

The design of our experiment includes two novel elements not seen in previous trampling studies. First, the substrate for our trampling experiment was the same sediment as the archaeological site that motivated the experiment. A similar experimental setup was used by Benito-Calvo et al. (2011), who simulated an archaeological sediment fabric by adding clasts to a nearby non-archaeological deposit. In contrast, we conducted our trampling experiment directly on the spoil heaps of archaeological sediment removed during the 2012 excavations at Madjedbebe. The use of site specific archaeological sediment adds a degree of realism to our trampling model. Interactions between the experimental artefact movement and trampling more faithfully resemble what might have happened in the past because we used the archaeological sediments. This ensures a close match for texture and penetrability between the experimental setup and the archaeological site. Our experiment still has many differences from the archaeological contexts; for example, we were not able to exactly match the compaction and fabric, or directional properties, of particular archaeological layers. Furthermore, we cannot be sure of the nature of the archaeological sediment at the time the artefacts were deposited and trampled in prehistory, because post-depositional processes have likely altered the sediment matrix. However, our field observations were that the spoil heaps closely resembled the structure, cohesiveness, permeability and moisture content of the archaeological deposits at Madjedbebe.

80 Our second novel element is the use of a system for classifying artefact form that is derived from 81 geological studies of the effect of particle form on their movement in sediments. Previous studies 
have used artefact length or mass as a proxy for artefact size to investigate the relationship between size and movement (e.g. Gifford-Gonzalez et al., 1985; Nielsen, 1991). As Eren et al. (2010) note, previous studies are not unanimous in demonstrating a relationship between artefact size and movement. This may be because length and mass by themselves are not especially sensitive variables when considering artefact movement. In studying the natural movement of clasts on the landscape, sedimentary geologists have developed a number of form quantification systems to investigate the transport history of sediments and characterize depositional environments (Benn et al., 1992; Blott and Pye, 2008; Oakey et al., 2005; Woronow and Illenberger, 1992). We adopted the simplest of these, the Zingg system (Zingg, 1935), to quantify artefact form and investigate its relationship with movement resulting from trampling. Although geological studies often refer to clast 'shape' when using the Zingg system (Barrett, 1980), this is a misnomer because shape strictly refers to the 'geometric properties of an object that are independent of the object's overall size, position, and orientation' (Mitteroecker2009; c.f. Dryden and Mardia, 1998). The Zingg system does not account for scaling, so in this paper we follow Blott and Pye (2008) and use 'form' to refer to an object's shape and size when using the

97 Zingg system.

98

\section{Madjedbebe}

Previously known as Malakanunja II, Madjedbebe is a sandstone rockshelter at the edge of the Magela floodplain in the Northern Territory, Australia. Archaeological excavations were conducted at Madjedbebe in 1973 (Kamminga et al., 1973), 1989 (Clarkson et al., 2015; Roberts et al., 1990), 2012 and 2015. The 1989 excavation produced Thermoluminescence (TL) and OSL ages of $52 \pm 11$ and $61 \pm 13$ ka associated with the lowest artefacts in the deposit (Roberts et al., 1990). The nearby site of Nauwalabila returned similar OSL ages, bracketing the ages of the lowest artefacts at between $53 \pm 5$ and $60.3 \pm 6$ ka (Bird et al., 2002; Roberts et al., 1994). These dates were questioned by Hiscock (1990) and Bowdler (1991), and later by Allen and O'Connell (2003) and Allen and O'Connell (2014). We have previously discussed these concerns in detail in Clarkson et al. (2015). Here we focus only on Hiscock's suggestion of the possibility of downward displacement of artefacts into sterile layers through human treadage.

Hiscock cited previous work (e.g. Stockton, 1973) that documented vertical movement of artefacts up to $16 \mathrm{~cm}$. If movements of this magnitude are common in sandy deposits such as Madjedbebe, then the artefacts associated with the 52 and 61 ka BP ages may have originally been deposited on a much younger occupational surface, and then been displaced downward into older deposits that are unrelated to human occupation. Hiscock's suggestion is that, for example, an artefact at the level of the $52 \mathrm{ka}$ age, $242 \mathrm{~cm}$ below the surface, may have originally been deposited during occupation at c. $200 \mathrm{~cm}$ below the surface. Using a loess regression on the ages published in Clarkson et al. (2015), we can interpolate a calibrated age of $23.3 \mathrm{ka} \mathrm{BP}$ for $200 \mathrm{~cm}$ below the surface. The difference in age of 29,000 years between 242 and $200 \mathrm{~cm}$ below the surface is substantial, and the ages at each depth have very different implications for how we interpret the stone artefact assemblage.

Previously, we reported on two factors that suggest this kind of downward displacement has not been extensive at Madjedbebe (Clarkson et al., 2015). First, we noted that there are several artefacts found within the same excavation unit that conjoin. We take these conjoins as evidence that downward displacement has had only a small effect on this assemblage. Second, we showed 
125 that there are clear changes in the abundance of raw materials over time. These changes would

126 be heavily obscured if there was substantial downward displacement of artefacts at Madjedbebe.

127 We believe it is unlikely that all the artefacts associated with the 52 ka age are actually $23.3 \mathrm{ka}$

128 old. However, we recognise the potential for artefact movement at the scale described by

129 Hiscock, and with this experiment we intended to get a better understanding of what components

130 of the lithic assemblage are most susceptible to this kind of downward displacement, and how

131 much of the assemblage might have been displaced to this extent.

\section{Materials and methods}

\section{Lithic assemblage}

134 We collected nodules of white quartz from the landscape and used hard-hammer direct

135 percussion to remove flakes, following a multi-platform reduction pattern. Quartz nodules occur

136 in the local sandstone scarp formation. Quartz artefacts are abundant in the archaeological

137 deposit, especially in the Holocene levels. We selected 30 flakes for the experiment, spray-

138 painted the artefacts bright orange and numbered them to make them easy to identify after each

139 trampling event. Metric data from the artefacts recovered in 1989 are not available, but we

140 produced the artefacts to be within the size range of the artefacts we were recovering from the

1412012 excavations (analysis of these artefacts is in progress).

\section{Form measurement}

143 The overall form of a clastic particle, such an artefact, is difficult to conveniently reduce to a

144 single measurement with precision and accuracy. In attempting to summarise an artefact's form, 145 archaeologists have developed a variety of methods for producing multivariate descriptions of

146 artefact form in two- and three-dimensions (eg. Grosman et al., 2008; Lycett et al., 2006). While 147 these methods have provided insights into reduction strategies and assemblage comparison, they 148 require specialised equipment (such as a three-dimensional scanner or photogrammetry 149 equipment) that was not available to us for our experiment. Instead, we used linear 150 measurements of artefacts obtained with vernier calipers to compute indices of artefact form. 151 These linear measurements can be used with the Zingg system to summarize artefact form. 152 Although there is extensive discussion on the question of the best clast form classification 153 method amongst geologists, there is little agreement (Blott and Pye, 2008; Woronow and 154 Illenberger, 1992). We chose the Zingg system because it is the simplest and most widely used 155 form classification system for geological clasts (Figure 1). 


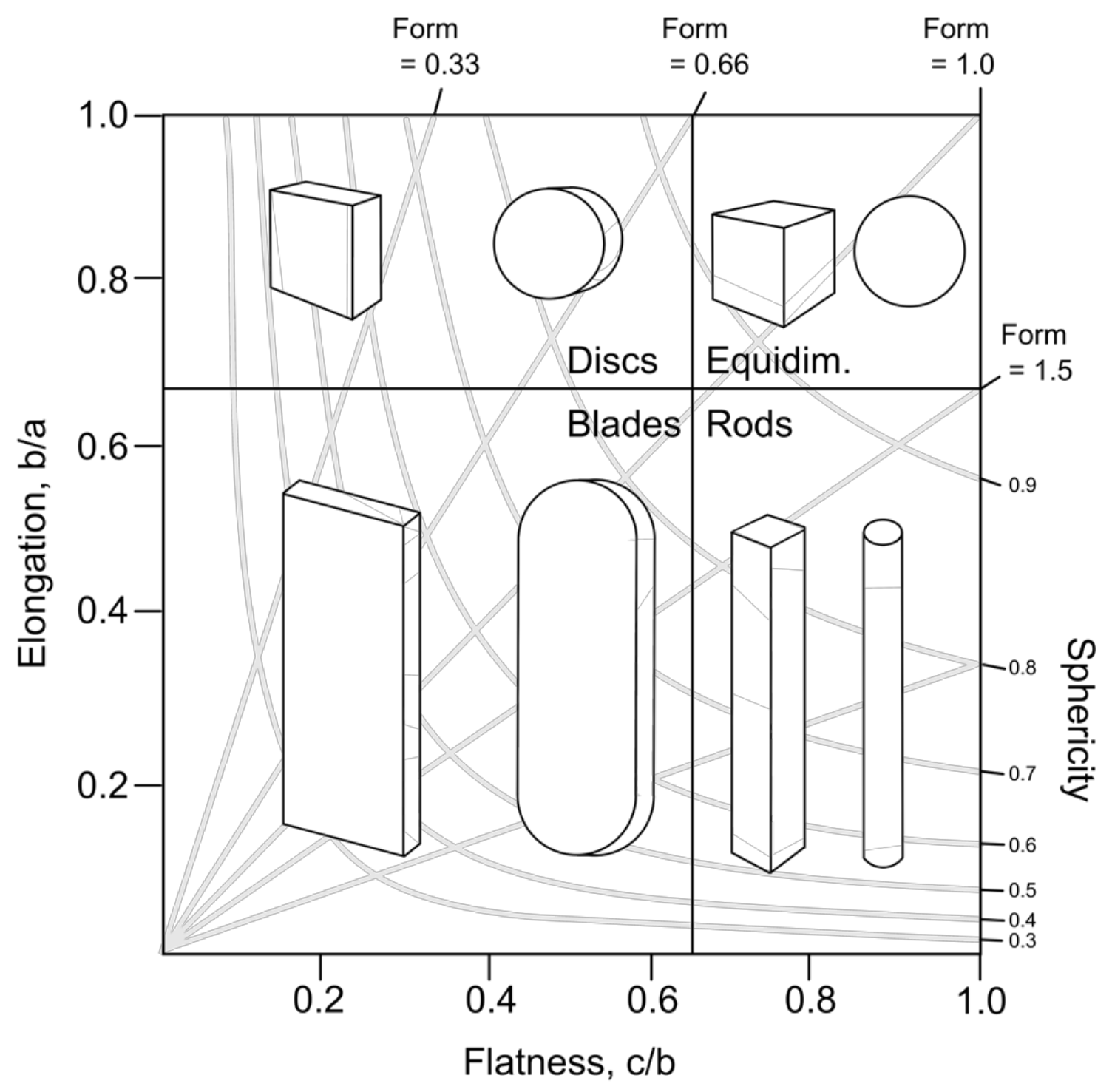

156

157 Figure 1 Schematic of the Zingg classification of geological clast form. 

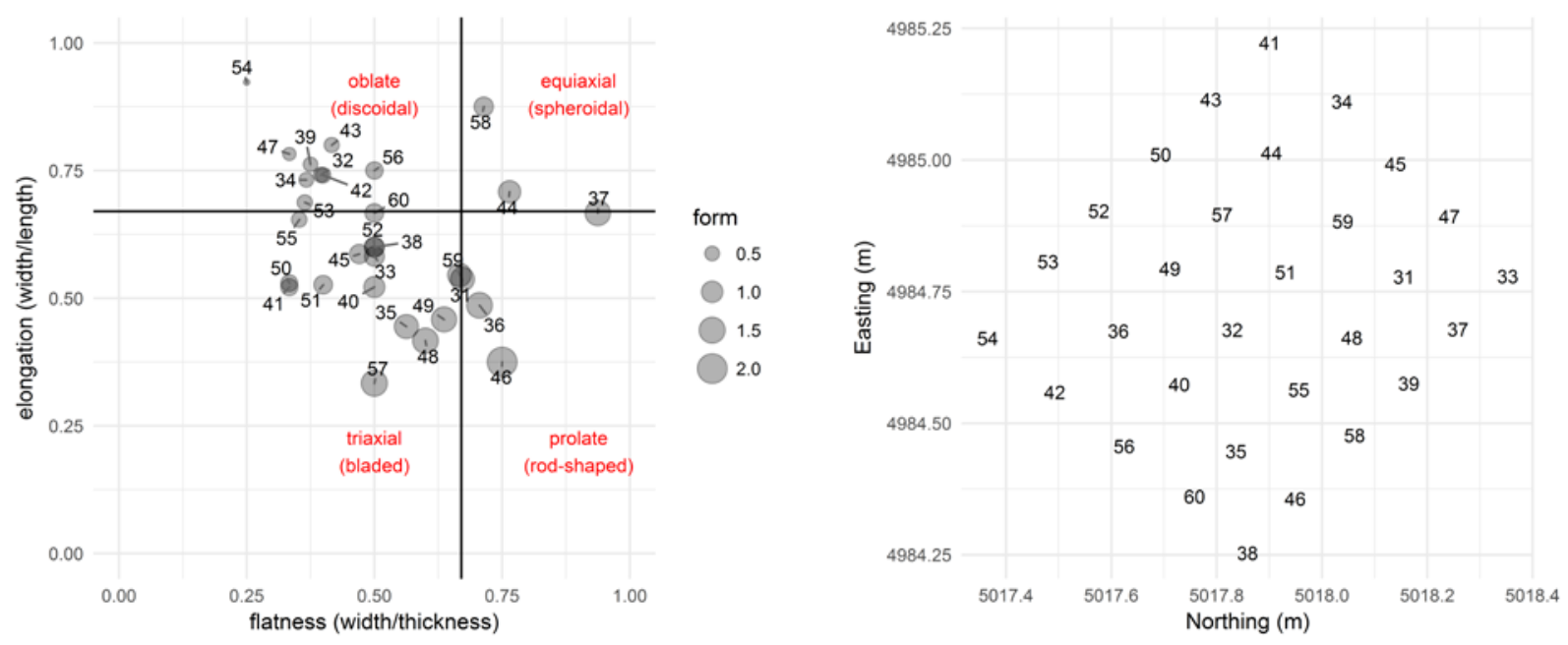

159 Figure 2 Left: Zingg Diagram classifying the form of the experimental artefacts. Right:

160 Starting locations of the experimental artefacts before trampling. Numbers on the plots

161 indicate the artefact identification number

162 Zingg indices are derived from the measurement of the three principal axes of the approximating 163 tri-axial ellipsoid. The three principal axes are the longest axis (denoted as $a$ ), the second longest 164 axis perpendicular to the longest axis $(b)$, and the third longest axis perpendicular to both $a$ and $b$ 165 (denoted as $c$ ). These measurements are not oriented with respect to the percussion axis of the 166 artefact. This is because the percussion attributes have little relevance to how the artefact 167 interacts with the sedimentary deposit during trampling. We simply measured the longest axis on 168 the artefact without regard to the flaking attributes, and then the longest axis that is perpendicular 169 to the first axis (the intermediate axis), and then the longest axis perpendicular to that (the short 170 axis). Volume is taken as the log of the product of $a, b$, and $c$. To obtain the Zingg indices for a 171 given artefact, we first determined the directions for principal axes of the artefact, then measured 172 the axes, and finally computed the axis ratios $b / a$ (Zingg's elongation ratio) and $c / b$ (Zingg's 173 flatness ratio). Zingg's form factor is flatness divided by elongation. A round or cubic artefact 174 will have a form factor equal to 1 , more elongated and thin artefacts will have a form factor 175 greater than 1, and a disc-shaped artefact will have a form factor less than 1 (Uthus et al., 2005). 176 The Zingg classifications of the artefacts used in the trampling experiment are presented in 177 Figure 2. 

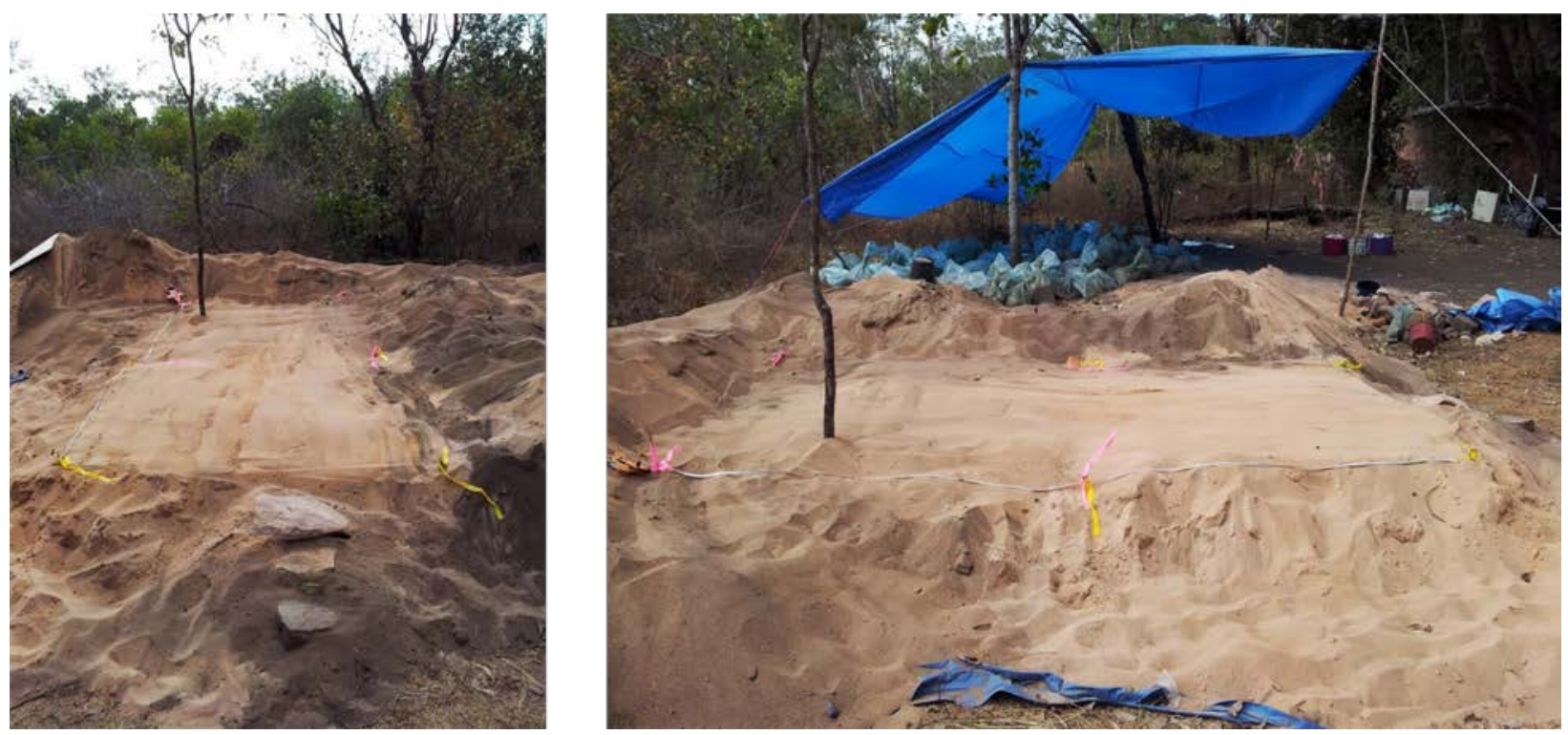

179 Figure 3 Views of the trampling area on the excavation spoil heaps.
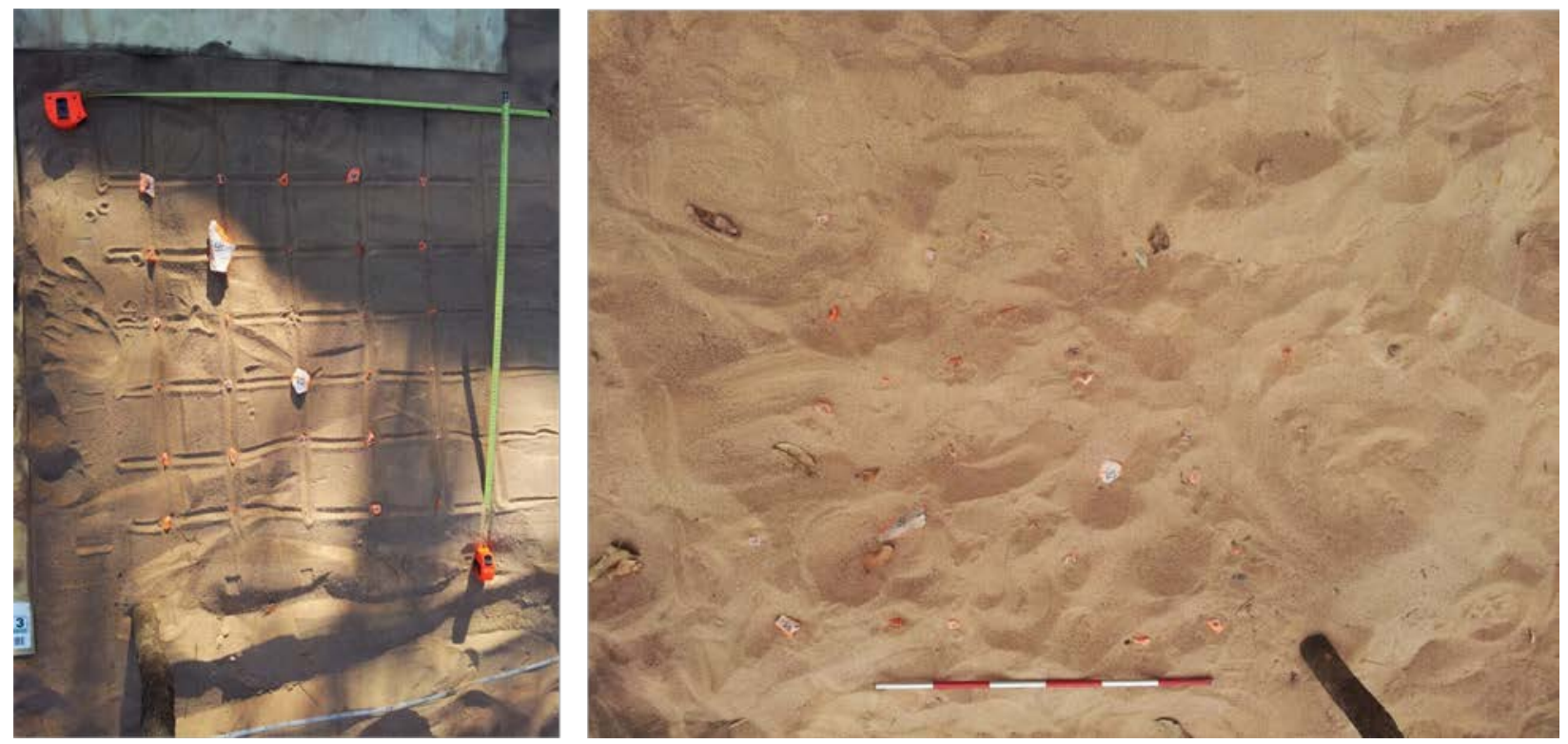

181 Figure 4 Close-up of trampling area showing the arrangement of artefacts before trampling

182 (left, grid spacing in $10 \mathrm{~cm}$ ) and after five minutes (right, scale rod bars are $10 \mathrm{~cm}$ )

\section{Trampling area, setup and events}

184 The trampling area was a level surface on the spoil heap of sediment removed during the 2012 185 excavations at Madjedbebe (Figure 3). After excavation, the sediment was sieved through $7 \mathrm{~mm}$ 186 and $3 \mathrm{~mm}$ mesh and dumped in a pile where it was stored until the excavation was backfilled. 187 We used shovels to create a compact level surface on the spoil heap of about three by three 188 meters. We waited until near the end of the excavation so that the trampling experiment could be 189 conducted on sediments removed from the lowest artefact-bearing deposits at Madjedbebe.

190 Waiting until the end of the excavation imposed time constraints on the experiment, limiting the 
191 scale of our study, because our excavation permit required immediate backfilling at the end of 192 the field season.

193 The artefacts were arranged on a one meter grid in the centre of the trampling area (Figure 4). The artefacts were positioned $10 \mathrm{~cm}$ from each other. The location of the artefacts was recorded

195 with a total station after they were placed on the grid, and after each trampling event. Of the thirty artefacts, 12 were over two centimeters long and recorded using two points at either end of their longest axis. The remaining 18 were recorded with a single point at their center of mass.

198 Each trampling episode consisted of an adult male walking barefoot at a constant natural slow walking speed. Our subject walked continuously in a clockwise circuit that included the trampling area for five minutes for each event. The walker crossed the trampling area in the same direction each time. At the end of five minutes, we carefully exposed the artefacts in situ with small leaf trowels, and used a total station to record their location, and for the larger ones, 203 orientation and inclination.

204 Trampling substrate

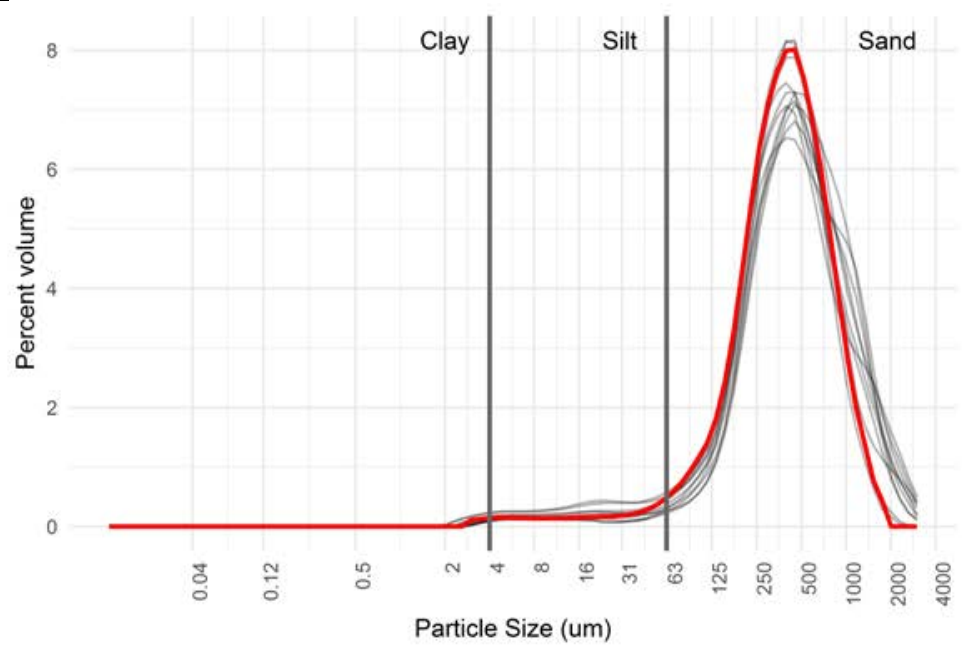

Figure 5 Particle size distributions of sediment collected from the trampling area (bold red line) and sediment collected from the archaeological excvation, 3-4 $m$ below the surface

The trampling area was a levelled section of the excavation spoil heap. The sediments came from 3-4 $\mathrm{m}$ below the surface, and had passed through $7 \mathrm{~mm}$ and $3 \mathrm{~mm}$ mesh before being dumped on the spoil heap. Although the sediment has been sieved, the texture of a sample taken from the spoil heap sediment remains identical to samples taken from the archaeological deposit, 3-4m below the surface (Figure 5). A permutation test for significant differences between any of these

214 Monte Carlo replications).

\section{$215 \quad$ Regression models and model visualisations}

216 To investigate how the artefacts' form and size variables predicts their movements during 217 trampling, we computed linear models (Chambers, 1991) for each combination of artefact 218 attribute and movement. For each model we visually inspected the independence of residuals, 219 homoscedasticity (constant variance of the residuals), and the distribution of the residuals to 
verify that our data are consistent with the assumptions of linear modelling. These plots are available in our SOM. Here we present visual summaries of several models, following Wickham et al. (2015). We introduce a new kind of plot, the model ensemble plot, to show model-level summary statistics. These model ensemble plots are an information-dense visualisation that is useful for exploring and comparing the importance of predictors in multiple models. These scatterplots show the models' adjusted $\mathrm{R}^{2}$ values, standardarised estimates and $\mathrm{p}$-values. The adjusted $\mathrm{R}^{2}$ values (on the vertical axis) shows model fit as an estimate of the proportion of variance explained by the variable under consideration (Faraway, 2014). Standardarised estimates (on the horizontal axis) are useful as measures of relationship strength for each variable because they can be interpreted as the change in response when the predictor changes by one standard deviation, if all other variables are held constant (Wickham et al., 2015). Standardarised estimates also show the slope of the regression line and thus the direction of the relationship between the variables (i.e. a positive or negative relationship). Our model ensemble plots show the models' $\mathrm{p}$-value of the models as proportional to the size of the data points (larger points indicate lower $\mathrm{p}$-values), with $\mathrm{p}<0.05$ values indicated by hollow points to highlight models with a very low probability of obtaining the observed data or more extreme data, given a hypothesis of no association between the variables (Greenland et al., 2016).

\section{Reproducibility and open source materials}

238 To enable re-use of our materials and improve reproducibility and transparency according to the principles outlined in Marwick (2016), we include the entire R code used for all the analysis and visualizations contained in this paper in our SOM at http://dx.doi.org/10.17605/OSF.IO/RTZTH.

241 Also in this version-controlled compendium are the raw data for all the tests reported here, as well as additional regression diagnostics and power tests. All of the figures, tables and statistical test results presented here can be independently reproduced with the code and data in this

244 repository. In our SOM our code is released under the MIT licence, our data as CC-0, and our 245 figures as CC-BY, to enable maximum re-use (for more details, see Marwick, 2016). 
246 Results 

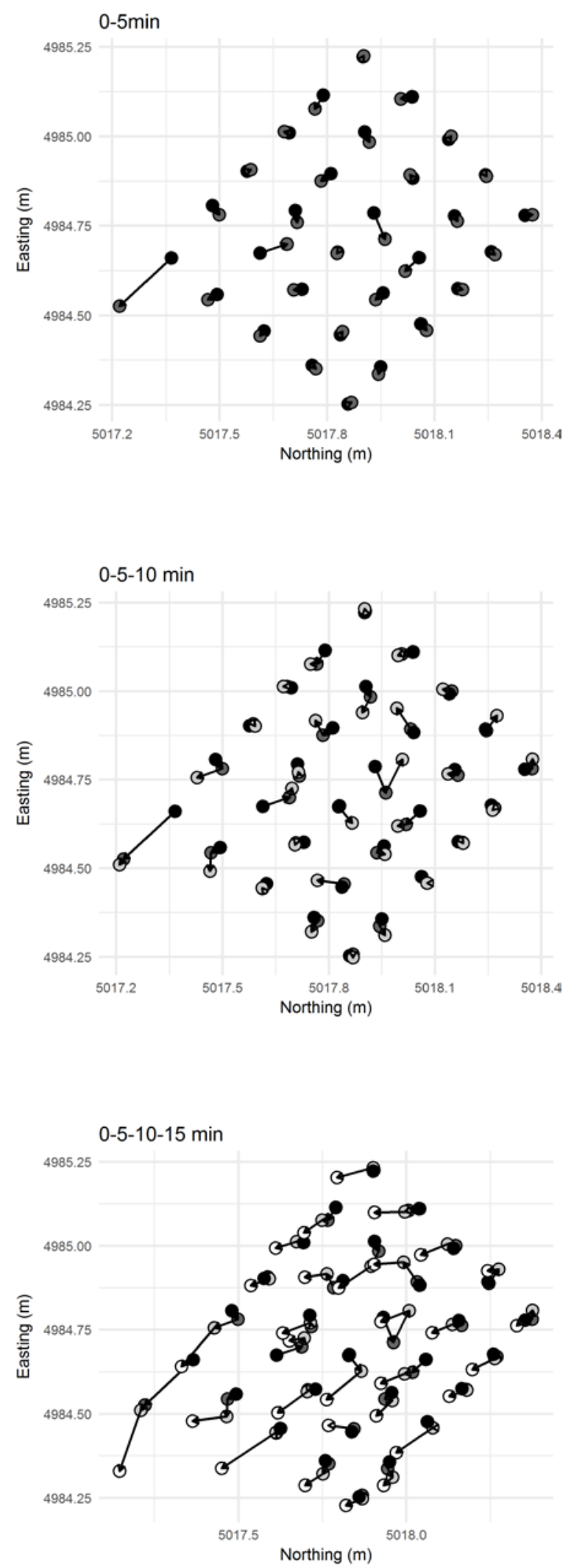
248 Figure 6 Plots of horizontal displacement of artefacts after 5, 10 and 15 minutes of trampling.

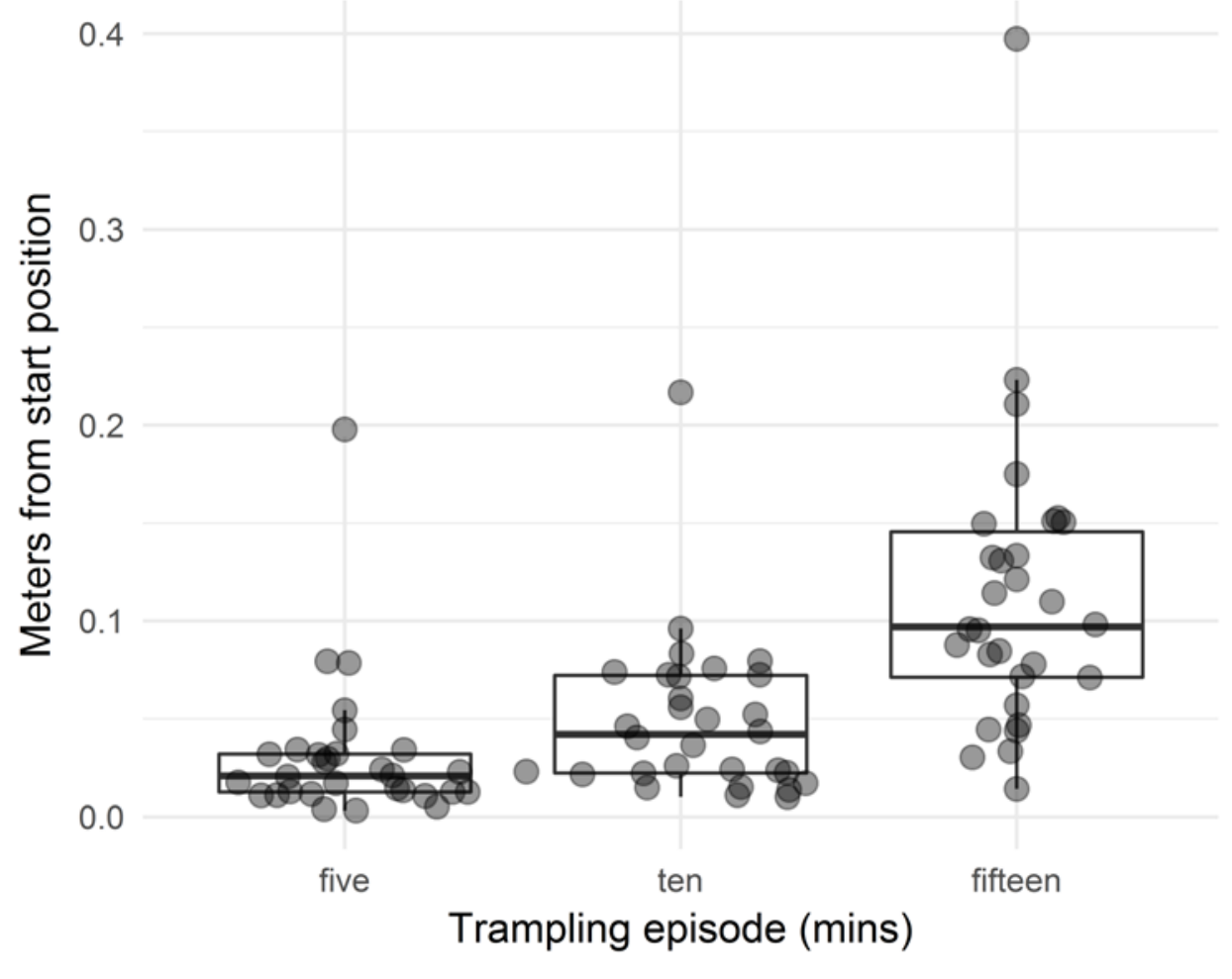

250 Figure 7 Distributions of horizontal displacements of artefacts after 5, 10 and 15 minutes of 251 trampling.

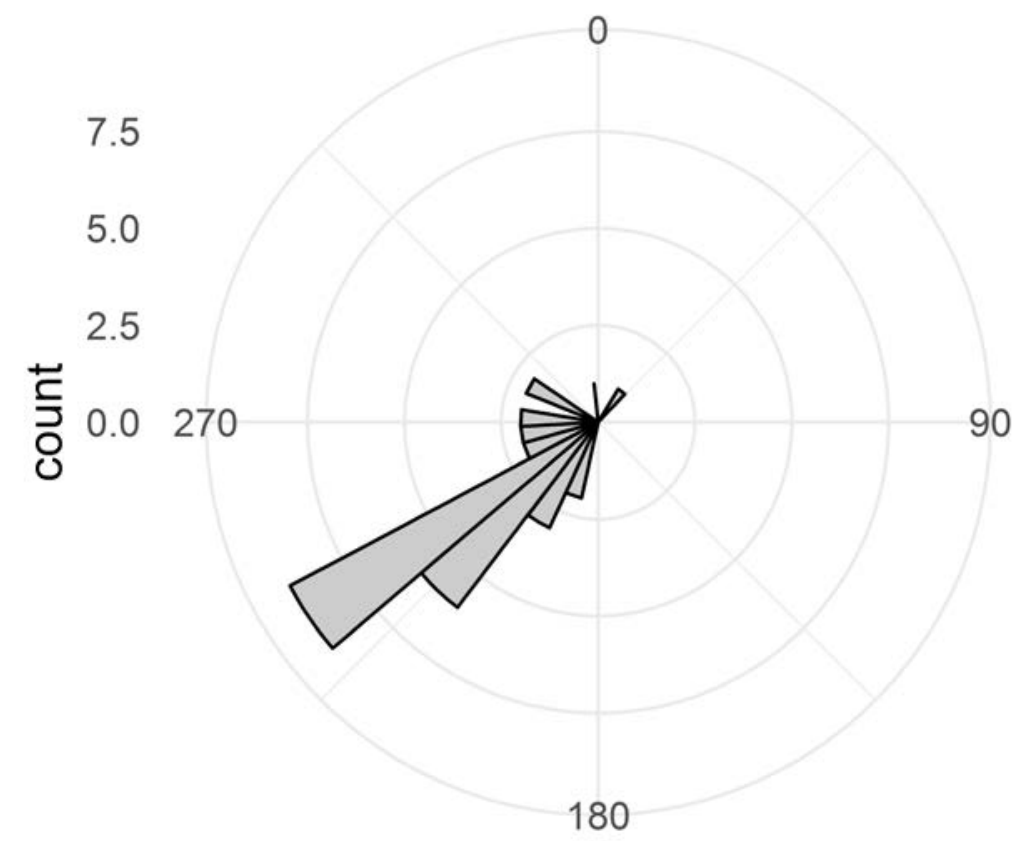


253 Figure 8 Histogram of directions of displacement of artefacts from their starting positions to 254 their locations after fifteen minutes of trampling. Zero degrees is due North.
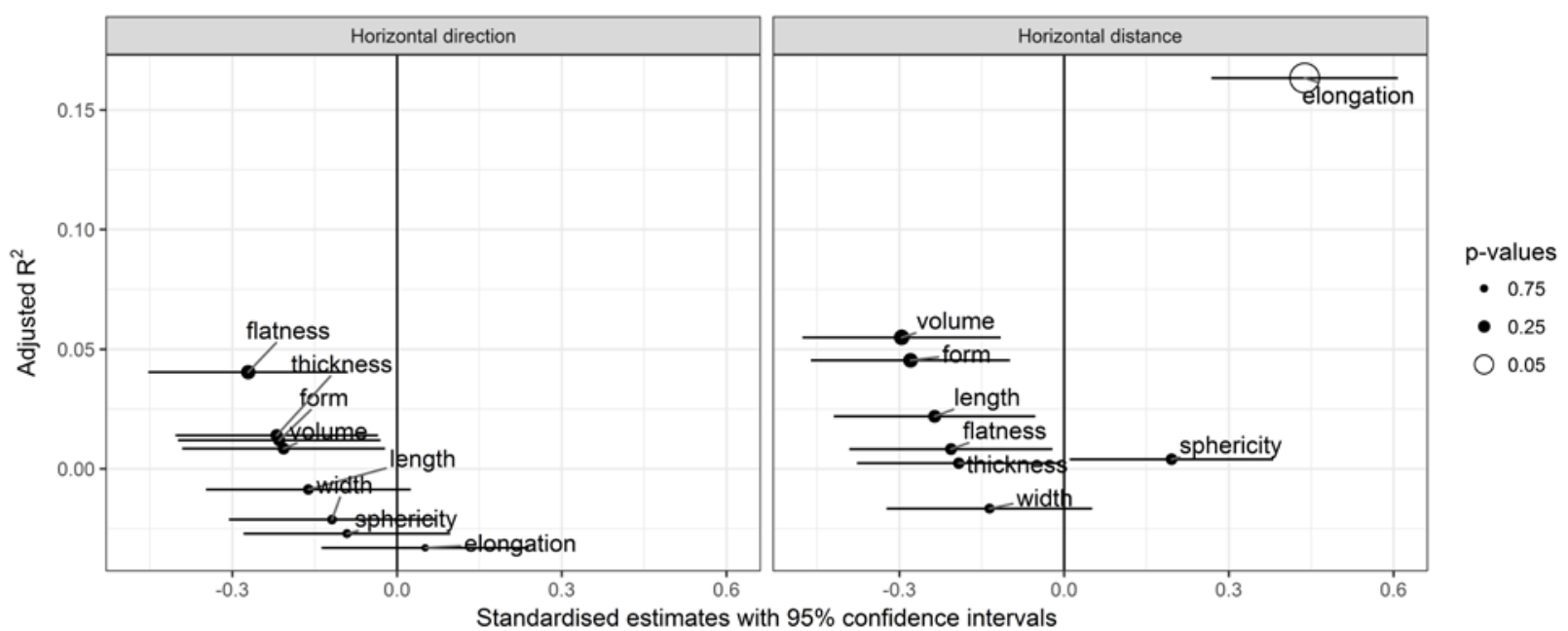

Figure 9 Linear models for a variety of predictors of the direction of horizontal direction (left) and distance (right) after fifteen minutes of trampling. Hollow data points indicate $p<0.05$.

\section{Horizontal displacement}

260 Figure 6 shows maps of the horizontal displacement of artefacts after five, ten and fifteen minutes. A variety of trajectories are visible, with some artefacts moving in a relatively straight line, others changing direction at each move, and one returning almost exactly to its start position. Figure 8 shows that after fifteen minutes, most artefacts have moved to a location opposite to the direction of walking across the area. None of the Zingg form variables are effective predictors of the direction of horizontal displacement (Figure 9).

Figure 7 shows the distributions of displacements from each artefact's starting position after each trampling interval. After fifteen minutes, the total horizontal displacement of all artefacts varied from $0.014 \mathrm{~m}$ to $0.397 \mathrm{~m}$ with a median of $0.097 \mathrm{~m}$, and median absolute deviation (a robust measure of variation) of $0.057 \mathrm{~m}$. Figure 9 provides a graphical summary of linear regression models to identify how well the Zingg form attributes predict the amount of horizontal displacement for each artefact after fifteen minutes of trampling. Elongation is the strongest predictor of horizontal displacement. The elongation relationship indicates that as width 274 trampling. 


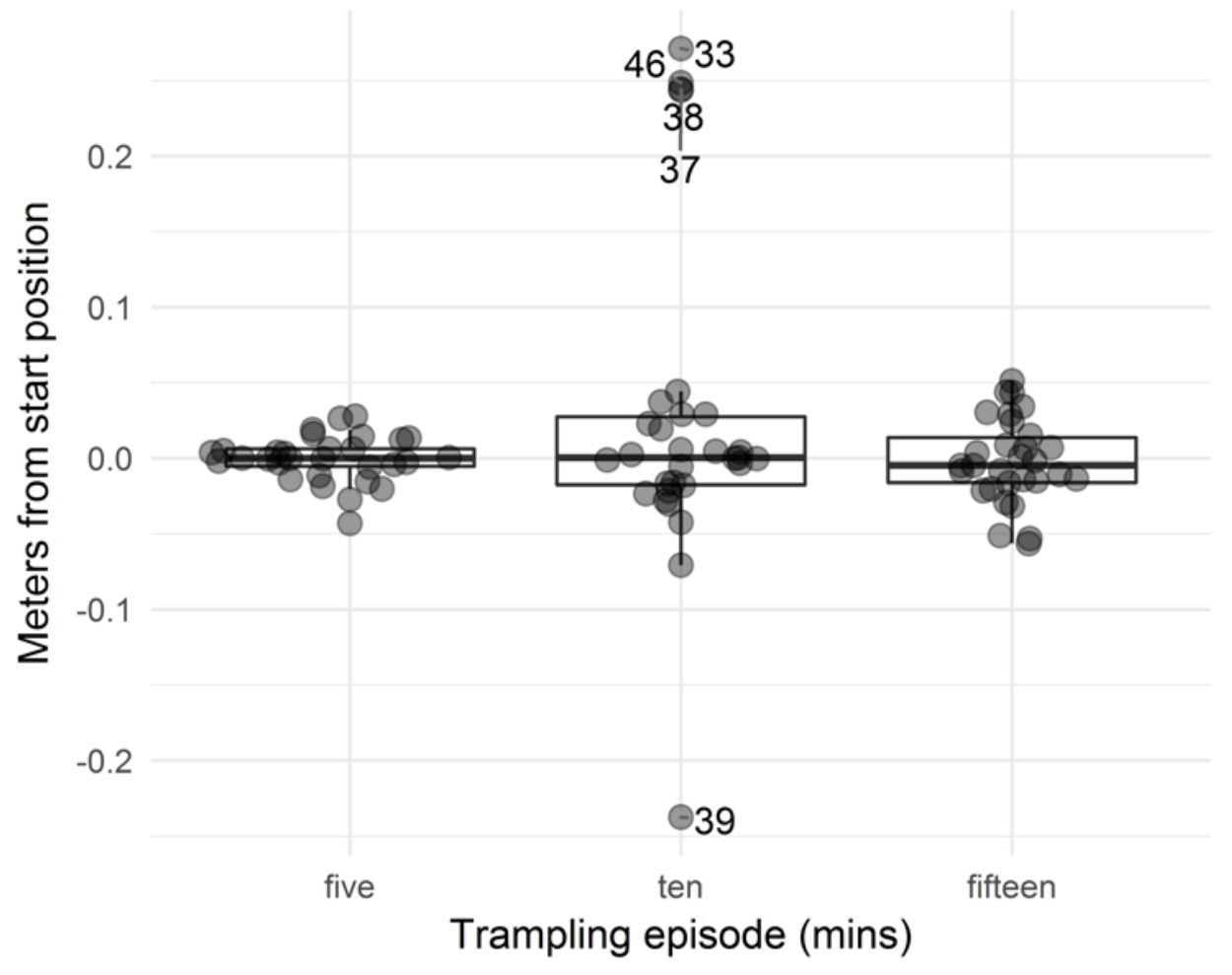

277 Figure 10 Distributions of vertical displacements of artefacts from their initial location to their location after 5, 10 and 15 minutes of trampling. Negative values indicate that the artefact is below its starting location, and positive values indicate that they are higher than the start because surface levels were raised by sand displacement.

The distributions of vertical displacements are shown in Figure 10. Five artefacts stand out as outliers, having moved $>0.2 \mathrm{~m}$ from their starting positions after ten minutes of trampling. These artefacts are located on the edge of the trampling area (Figure 2) and their high vertical displacement is a result of heavier steps taken while walking over the edge of the trampling area as the walker adjusted their stride after ascended the slope onto the sand pile where the trampling area was located. At the end of the third trampling episode these outlying artefacts had returned closer to their starting locations, in part because the trampling moved them horizontally further from the edge of the trampling area and away from the slope. Excluding these outliers, the vertical displacement of the artefacts is summarised in Table 1.

290 Table 1 Summary of absolute (ie unsigned) vertical displacement of trampled artefacts (units are meters, $M A D=$ median absolute deviation)

\begin{tabular}{lrrrr} 
time & Minimum & Maximum & Median & MAD \\
\hline five & 0.000 & 0.043 & 0.006 & 0.009 \\
ten & 0.000 & 0.071 & 0.018 & 0.018 \\
fifteen & 0.001 & 0.056 & 0.016 & 0.016
\end{tabular}


292 Figure 11 shows that unsigned (or absolute, without respect to the upwards or downwards 293 direction) vertical displacement has no strong predictors among artefact form and size variables. 294 However, artefact volume, width, length and thickness are all signficant predictors when the direction of vertical movement is considered. Bigger artefacts tend to move above their starting position, and smaller artefacts tend to move below it.

297 The vertical angles of artefact displacement cluster close to horizontal (Figure 12). This is expected given that the horizontal displacement values are much greater than the vertical displacement values.
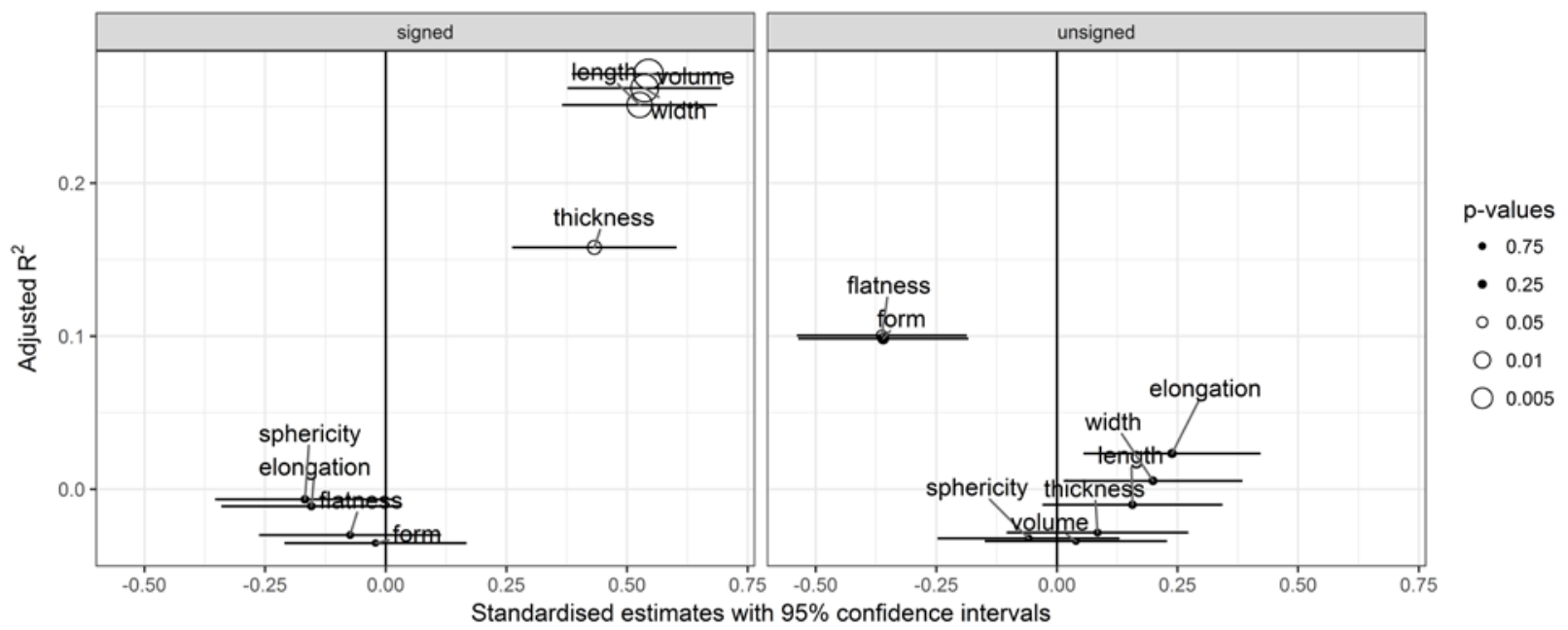

301 Figure 11 Linear models for a variety of predictors of signed and unsigned (ie. absolute) vertical displacement after fifteen minutes of trampling. Hollow data points indicate $p<0.05$.

303 Positive estimate values indicate positive correlations. 


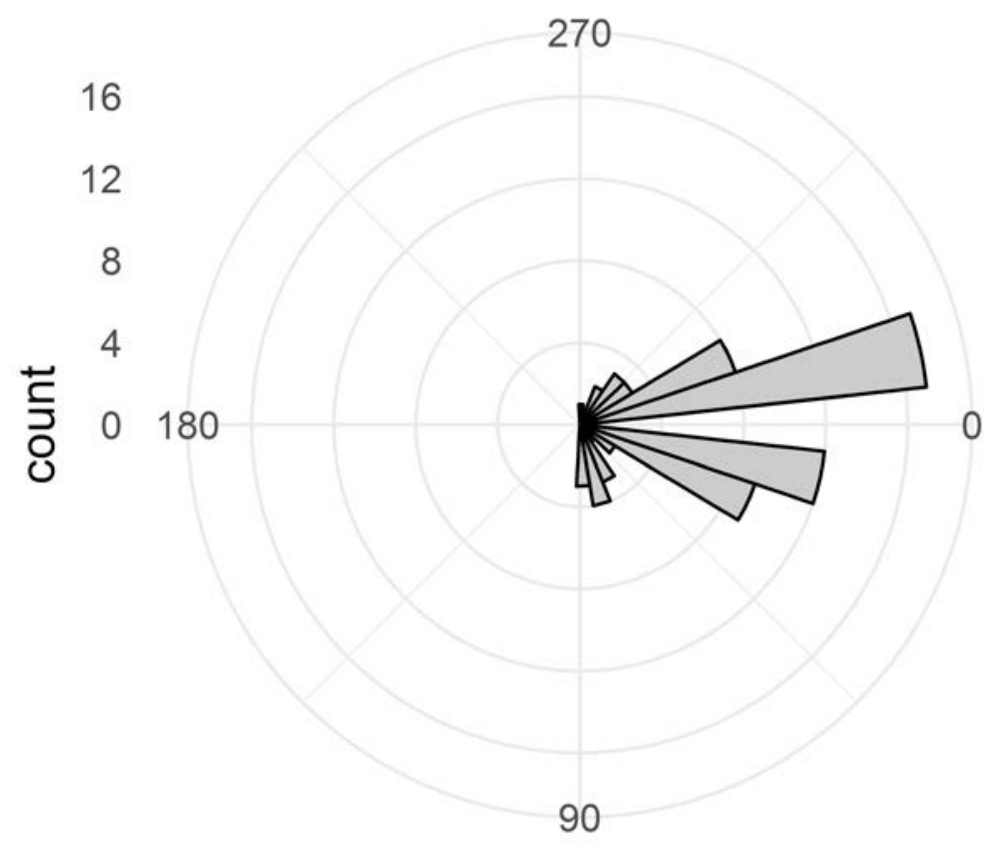

305 Figure 12 Vertical angles of artefact displacement, or the vertical angle that the artefact moved from its starting point to its location after each trampling event. Zero degrees is

307 horizontal

308 Orientation and Plunge

309 Our sample includes 14 artefacts with two or four total station points, enabling measurements of changes in the orientation of the artefact (ie. changes in the bearing of the long axis of the artefact) and plunge (ie. the vertical angle from the horizontal plane of the long axis of the artefact). Figure 13 shows that these changes are generally small, with most changes clustered around zero degrees (i.e. the bearing/plunge angle that the artefact was at before trampling). Watson-Williams tests for homogeneity of means (Pewsey et al., 2013) show no significant differences between starting and final orientations after 15 minutes of trampling $(\mathrm{F}=0.697, \mathrm{p}=$ $0.412)$, but show significant differences in plunge angles $(F=9.222, p=0.005)$. Only changes in orientation are significantly predicted by artefact form and size attributes; there are no significant predictors for changes in artefact plunge angle (Figure 14). Similar to vertical displacement, artefact volume, width, length and thickness are all significant predictors of the magnitude of change in artefact orientation. Bigger artefacts tend to be rotated further from their original 321 bearing.

322 Correlations of these changes in orientaton and plunge with horizontal and vertical distances and angles are shown in Table 2. Orientation and plunge are not strongly correlated with any other measurements of artefact movement. Increased distances of artefact displacement do not appear to have any effect on artefact orientation and plunge. Vertical angle is strongly negatively correlated with horizontal distance and vertical distance. This indicates that as the artefact moves further from its starting location, the vertical angle is smaller (i.e. closer to horizontal). Vertical 
328 and horizontal distance have a moderately strong positive relationship, indicating that the magnitude of displacement is proportional in both horizontal and vertical axes.

Change in artefact orientation

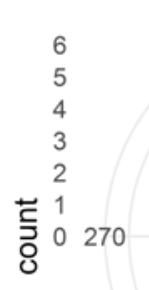

Change in artefact plunge

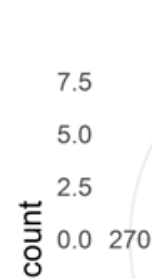

180

Figure 13 Histograms of changes in artefact orientation (left) and artefact plunge (right) after each trampling event. Zero degrees refers to the starting orientation bearing or plunge angle for each artefact. For artefact plunge, a change 0-180 degrees is a change towards a more vertical orientation, and a change 180-360 is a change towards a more horizontal orientation.
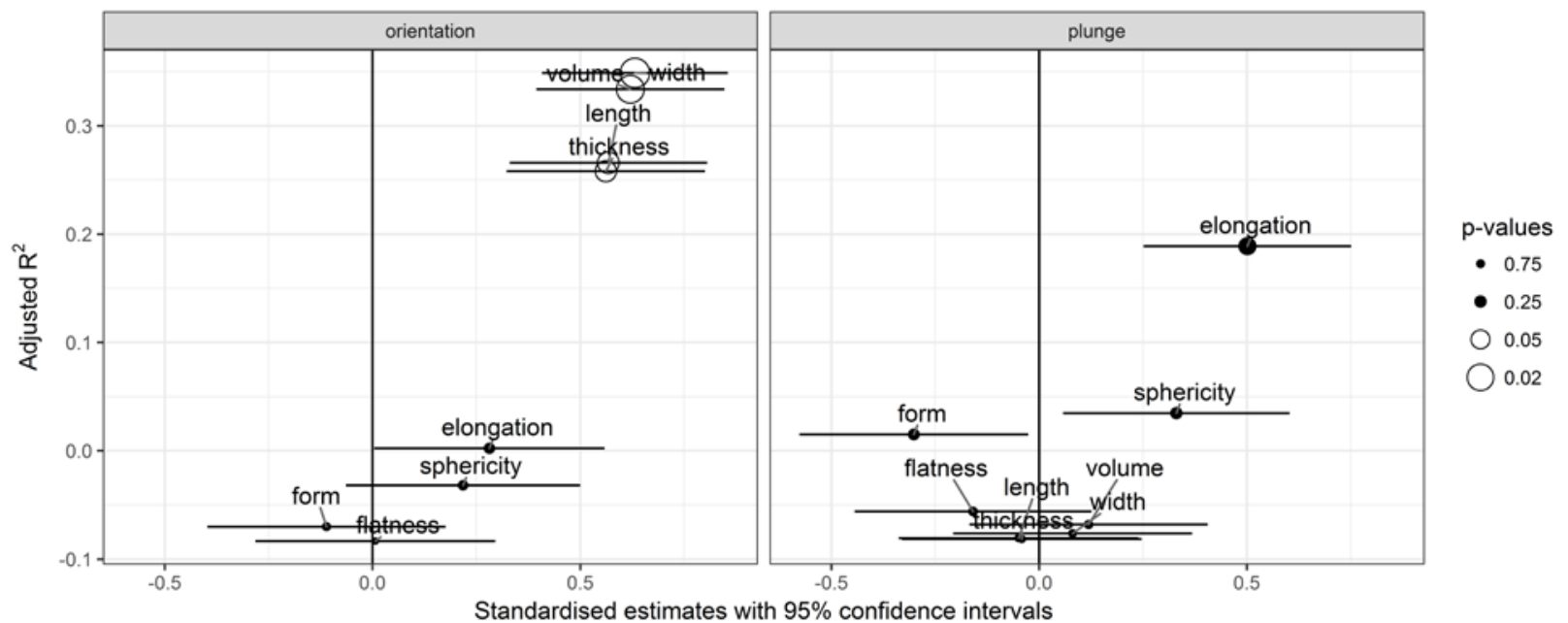

337 Figure 14 Linear models for a variety of predictors of changes in artefact orientation bearing and plunge angle after fifteen minutes of trampling. Hollow data points indicate $p<0.05$.

340 Table 2 Pearson's correlation coefficients for changes in artefact plunge and orientation, and

341 for values of horizontal and vertical distance, horizontal bearing and verticle angle after

342 fifteen minutes. Values in parentheses are p-values. Strong significant correlations are in bold.

$\begin{array}{lllll}\text { Plunge } & \begin{array}{l}\text { Horizontal } \\ \text { distance }\end{array} & \begin{array}{l}\text { Horizontal } \\ \text { bearing }\end{array} & \begin{array}{l}\text { Vertical } \\ \text { distance }\end{array} & \begin{array}{l}\text { Vertical } \\ \text { angle }\end{array}\end{array}$




\begin{tabular}{|c|c|c|c|c|c|}
\hline Orientation & $\begin{array}{l}-0.02 \\
(0.94)\end{array}$ & $0.1(0.74)$ & $-0.22(0.44)$ & $0.11(0.71)$ & $-0.15(0.61)$ \\
\hline Plunge & & $0.28(0.33)$ & $0.37(0.19)$ & $0.33(0.25)$ & $-0.31(0.28)$ \\
\hline $\begin{array}{l}\text { Horizontal } \\
\text { distance }\end{array}$ & & & $0.27(0.35)$ & $0.62(0.02)$ & $\begin{array}{l}-0.74 \\
(<0.01)\end{array}$ \\
\hline $\begin{array}{l}\text { Horizontal } \\
\text { bearing }\end{array}$ & & & & $0.49(0.07)$ & $-0.44(0.12)$ \\
\hline Vertical distance & & & & & $\begin{array}{l}-0.88 \\
(<0.01)\end{array}$ \\
\hline
\end{tabular}

\section{Discussion}

344 Comparison with previous experimental results

345 Previous trampling studies show little agreement about the relationship between artefact size and 346 displacement due to trampling. Stockton (1973) identified moderate size sorting resulting from trampling, with mean artefact mass decreasing with depth. Conversely, Moeyersons' (1978) wetting-drying experiments in Kalahari sands at Gombe found that the heaviest aretfacts moved the largest distances downward in the deposit. Wilk and Schiffer (1979) reported a similar relationship on paths in vacant lots, with larger artefacts having been more frequently trampled off the paths. Similar patterns have been observed in more general studies of site formation. For example, smaller rather than larger pieces of flaked stone, bone and charcoal are more likely to be found in situ after sweeping and other site maintainance activities have occurred (Keeley, 1991; Stevenson, 1991).

On the other hand, Villa and Courtin (1983) reported from their trampling experiment that artefacts lighter than $50 \mathrm{~g}$ were relatively mobile, moving vertically more than pieces heavier than $50 \mathrm{~g}$, which tended to stay on or near their original location. They report no obvious correlations for horizontal movement and artefact size, but observed that while many lighter artefacts did not move far from their original locations, lighter pieces tended to move further than heavier artefacts. Gifford-Gonzalez et al. (1985) found that none of the artefact metric variables they recorded correlated significantly with depth below surface (although no summary statistics or raw data are provided to support this claim). However, they noted that their results may not be decisive because of the rarity of very large and very small artefacts in their sample (their artefacts had a maximum unoriented length of 3-13 mm, the majority were 3-6.5 mm). They further propose that the high dynamic range of trampling (i.e. highly vigorous) in their experiment may have prevented patterns from emerging in the interaction between the artefacts and the moving sediment.

368 In a trampling experiment conducted by Driscoll et al. (2015) vertical movements of artefacts were mostly less than $1 \mathrm{~cm}$, with rare occurrences of greater than $2 \mathrm{~cm}$. They observed no clear relationship between artefact size and vertical distance. In their low foot-traffic zone the largest artefacts had the greatest change in mean depth, while in the high traffic zone the smallest artefacts moved further. For horizontal movement, Driscoll et al. noted a clear pattern of the largest, thickest, and heaviest artefacts moving the greatest mean distance. But when they 
excluded the largest artefacts from the analysis (i.e. those with a maximum length of 35-40 mm, out of a total range of $10-40 \mathrm{~mm}$ in their sample), the relationship between distance and artefact size became very weak. Eren et al. (2010) also report no relationship between artefact size and horizontal displacement, and only a weak positive correlation between artefact size and vertical displacement.

Table 3 Summary of significant $(p<0.05)$ and strong $(r>0.6$ or $r<-0.6)$ correlations of artefact size and form variables with the Cook's Distance values for each linear model.

\begin{tabular}{llrl} 
Variable & Movement & Pearson correlation & p-value \\
\hline Length & Orientation & 0.854 & $<0.001$ \\
Length & Plunge & 0.648 & 0.012 \\
Thickness & Orientation & 0.789 & 0.001 \\
Thickness & Plunge & 0.676 & 0.008 \\
Volume & Plunge & 0.637 & 0.014 \\
Width & Plunge & 0.663 & 0.010
\end{tabular}

381 Our results similarly showed weak, non-significant relationships between artefact length, width and thickness (as defined above) and horizontal distance, horizontal direction of movement, and unsigned (ie. absolute) vertical displacement after trampling. However, if we consider the direction of vertical movement, we found a positive significant relationship with length, width, thickness and volume, indicating that trampling causes larger artefacts to move above their starting position. That said, the adjusted $\mathrm{R}^{2}$ values on these relationships are low (0.1-0.3), indicating that these artefact metrics predict only $10-30 \%$ of the observed variation in vertical 388 distance moved after trampling.

Our artefacts ranged in maximum unoriented length from $8 \mathrm{~mm}$ to $108 \mathrm{~mm}$, a much greater range than reported by Gifford-Gonzalez et al. (1985) and Driscoll et al. (2015). While Driscoll et al. noted a strong effect of larger artefacts in horizontal movement, we did not find a similar effect. Table 3 shows that in our experiment the larger artefacts have an outsize influence only on the models describing artefact orientation and plunge (full details are reported in the SOM). We computed the Cook's (1979) distance for each artefact in each model to identify the artefacts whose removal from the model would change the model coefficients the most (Fox and Weisberg, 2010). Then we computed the correlation between an artefact's volume (as a measure of artefact size) and its Cook's distance value in each model. Strong significant correlations were found in the models using artefact length and thickness to predict change in artefact orientation, and for using length, thickness, width and volume to predict change in artefact plunge. There were no signficant correlations between artefact volume and Cook's distance in models predicting horizontal or vertical movement, so bigger artefacts do not seem to have had an unusual influence on these relationships. One possible explanation for the difference between our findings and those of Driscoll et al. is the trampling substrate. Perhaps the sandy sediments of the our experiment had more of a buffering affect on artefact movement, compared to the compact, stony substrate reported by Driscoll et al.

406 Artefact form variables have received limited consideration in previous studies. In his 407 experiment with five artefacts, Moeyersons (1978) observed how artefacts with the highest 408 weight/vertical projection surface ratio moved the greatest vertical distance. Gifford-Gonzalez et 
al. (1985) similarly examined the orientation of the artefact edge and the ground surface, but did not identify any relationship between this orientation and vertical displacement due to trampling. In their experiment to investigate post-depositional processes on an experimental knapping assemblage deposited on sand dunes, Barton and Bergman (1982) observed that wider, flatter artefacts moved less, and artefacts that moved further down the deposit tended not to be horizontally oriented.

415 In our experiments artefact form variables were significant predictors for horizontal distance (elongation has a positive relationship) and signed vertical distance (volume, width, length and thickness). Artefacts with high elongation values are more disc-like or equidimensional (depending on their flatness values), and artefacts with high volume, width, length and thickness are larger overall (Figure 2). These results agree with those from from Barton and Bergman's (1982) observations that wider, flatter (i.e. discoidal) artefacts moved less. However, the adjusted $\mathrm{R}^{2}$ values for our models range between 0.1 and 0.3 , indicating that although form variables have a statistically significant role in influencing artefact movement during trampling, they have limited value for making specific predictions how far artefacts with certain form attributes have moved due to prehistoric trampling. Our results indicate that it is not possible to use artefact form and size to identify artefacts that have been trampled away from their original location.

Simulation of long-term trampling by resampling

427 A common limitation of experimental studies of taphonomic processes such as trampling is the short time scale of experimental observations relative to the long time scales often represented by archaeological sites (Dominguez-Solera, 2010). The duration of our experiment was particularly short due to the unique use of the archaeological sediments in the spoil heap as the trampling substrate. In general, we lack experimental data on what patterns might emerge after years of occasional trampling that might result from, for example, seasonal use of a rockshelter. To explore what might have happened if our experiment had run for a long time, we can simulate the effects of a large number of trampling events by resampling many times from the observed trampling event measurements. Yorsten et al. (1990) used this approach to the study the effect of ploughing on horizontal distributions of ceramic sherds. They observed sherd locations at the Butser Ancient Farm Research Project over six years, and simulated locations for various time intervals up to 200 years to show that ploughing can substantially alter surface distributions of ceramics.

Taking a similar approach, we computed the difference in co-ordinates of each artefact's location after each of the three trampling events that we observed. The difference in co-ordinates are the co-ordinates of an artefact's starting location minus the co-ordinates of its position at the end of the trampling event. To simulate artefact movement by trampling, we take each artefact in our sample and we randomly select one of its three observed differences in co-ordinates, and compute a new position for the artefact by adding these randomly selected co-ordinates to the artefact's starting co-ordintates. Then at this new position, we make another random selection from the three co-ordinate pairs, and add these co-ordinates to compute a new position. In each iteration we are taking the observed measurements specific to each artefact, and using them to compute new theoretical, but plausible, positions after a simulated trampling event. This differs slightly from Yorsten et al. (1990), who used a probability distribution to displace each artefact in their simulation. Instead, we use the observed displacement values directly, because the displacement of the artefacts is determined, in part, by the specific form and size of each artefact. 
If we repeat this process of computing new positions many times, we can simulate the movement of artefacts after a large number of events, which is challenging to do in practice.

Simulations such as this are a trade-off between a desire to be relevant to real-world conditions, and the limitations imposed by assumptions and simplifications necessary to make the modelling tractable (Aldenderfer, 1991; Kohler, 2015; Lake, 2014). In our model we assume that the surface that the artefacts rest on is clear, stable and flat, and that there is not acculumuation or erosion of the substrate. Obviously this is unrealistic, but because we do not have high resolution data on the relationship between sediment accumulation rates and site occupation rates (e.g. was the site was visited one week every ten years, or three hours every month? Were sedimentation rates continuuous or strongly seasonal? Were there cycles of erosion and deposition, or contant

464 One detail that is important for improving the realism of this simulation is that the impact of 465 trampling activity declines with depth from ground surface, such that an artefact may eventually be trampled so deep below the surface that it is no longer in range of trampling disturbance. To identify a realistic value for this depth, we computed the parameters for a gamma distribution to fit the distribution of observed values of artefact displacement below their starting locations (several other distributions were also explored, details are available in the SOM). Using this distribution, we determined that $99.9 \%$ of observations are above a depth of $0.151 \mathrm{~m}$ below the surface. This depth is consistent with our field observations of the depth of the upper 'dry layer' of mobile sands in the alluvial soils of Magela floodplain where Madjedbebe is located. It is also close to the value of $16 \mathrm{~cm}$ for the maximum depth of the glass artefacts observed by Stockton (1973) in his experiment in the sandy deposits of Shaw's Creek rockshelter. Other experiments report lower values for maximum vertical displacement of trampled artefacts, for example, $3 \mathrm{~cm}$ observed by Gifford-Gonzalez et al. (1985), $8 \mathrm{~cm}$ by Villa and Courtin (1983), $1.5 \mathrm{~cm}$ by Nielsen (1991), and $21 \mathrm{~cm}$ by Eren et al. (2010, where trampling was by buffalo rather than humans). We used this gamma distribution to scale down the intensity of trampling as the depth of the artefact increased during the simulation. As an artefact in the simulation moves deeper, we multiplied the displacement co-ordinates of each iteration by the inverse probability of finding an artefact at that depth.
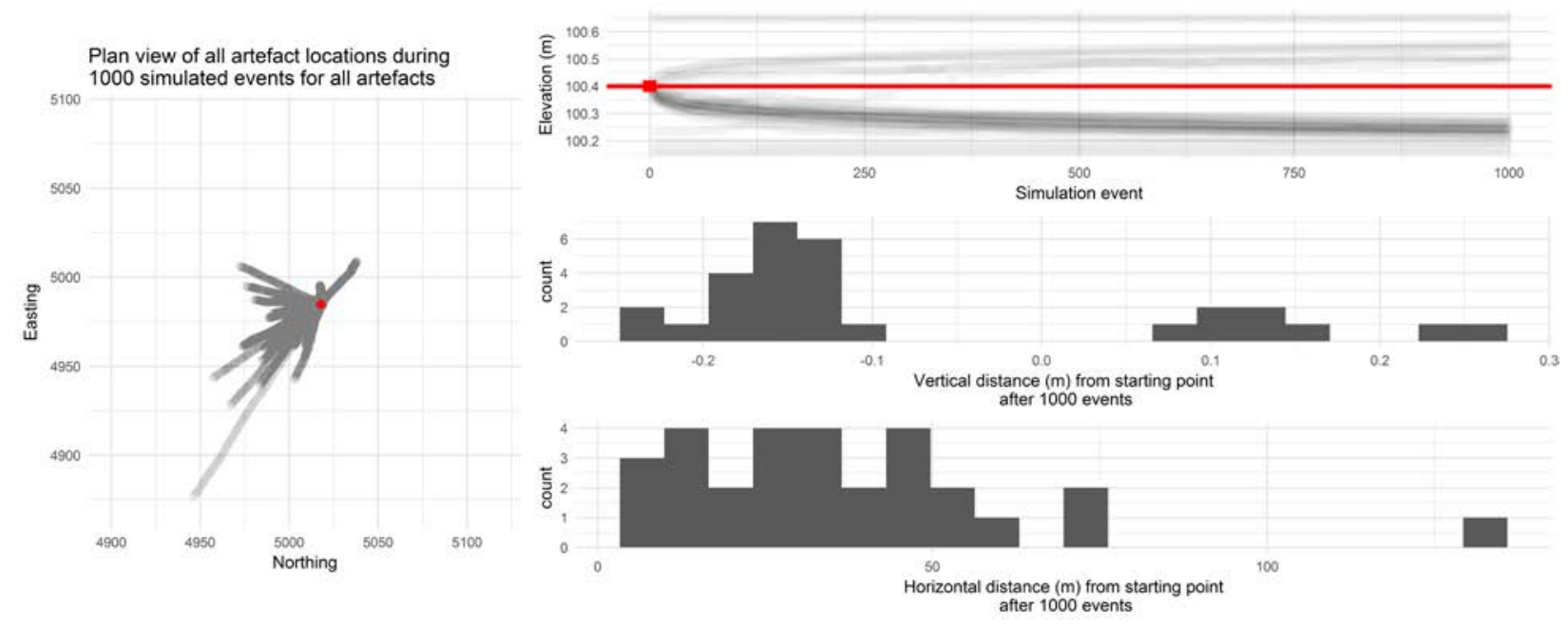

482 
Figure 15 Summary of a simulation of artefact trampling. Left panel shows the plan view of artefact locations during the simulation, the red area indicates the starting locations of the artefacts. Upper right panel shows change in artefact elevation during the simulation, the horizontal red line shows the mean starting elevation of the artefacts, and the short vertical red line shows the range of starting elevations for the artefacts. Middle right panel shows the distribution of vertical displacement of artefacts after 1000 simulated trampling events. Lower right panel shows distribution of horizontal displacement of artefacts after 1000 simulated trampling events.

491 Figure 15 summarises the results of our simulation (additional figures are included in the SOM). Horizontal movement is strongly determined by the direction of walking, with most artefacts between 0 and $50 \mathrm{~m}$ from their original location. In the left panel of Figure 15 we can see two diffuse scatters to the upper and lower left of the starting location. This simulation demonstrates how trampling of a concentrated artefact scatter can result in low density scatters over a large area, and isolated finds of artefacts up to $100 \mathrm{~m}$ from their original location. The vertical distribution of artefacts at the end of the simulation shows that most artefacts end up 0.1 to $0.2 \mathrm{~m}$ below their starting positions. Most artefacts in the simulation move quickly towards the asymptotic depth where they are out of range of further trampling, and do not change their vertical location much after the first few hundred trampling events.

501 This simulation has two implications for artefacts in sandy deposits. First is that the horizontal patterning of artefacts may be strongly determined by the directions and duration of trampling events. This means that horizontal clusters of artefacts observed on real-world archaeological surfaces may be the result of trampling rather than prehistoric behaviour. Secondly, the vertical distribution of artefacts is also altered by trampling, but rarely more than 0.1 to $0.2 \mathrm{~m}$ above or below their starting locations. These findings are consistent with the observations of GiffordGonzalez et al. (1985) and Villa and Courtin (1983) who report a turbulent 'zone of constant circulation' of loose, mobile substrate where trampling affects the location of artefacts. They also report artefacts migrating down to a stable zone where they are out of reach from further trampling, just as we observed here. One real-world application of this is that in a weakly stratified sandy deposit an assemblage of artefacts representing an archaeological instant (i.e. a few hours or days) may, after some trampling, be distributed across a depth of up to 0.1 to $0.2 \mathrm{~m}$ below its original position. We recognise that artefacts could still realistically move much deeper than the depths observed here, but this would be highly unlikely to result from trampling, and more likely be a result of qualitatively different processes, such as burrowing.

517 To return to the archaeological question that motivated this experiment, we can investigate the

\section{Implications for the age of artefacts at Madjedbebe} effect of 0.1 to $0.2 \mathrm{~m}$ of vertical spread of artefacts on determining the age of artefacts at Madjedbebe. The $0.4 \mathrm{~m}$ vertical migration proposed by Hiscock for artefacts Madjedbebe is much greater than what experimental data indicates would result from trampling. We acknowledge, of course, that trampling is not the only process that can vertically migrate artefacts, and may even be one of the least disruptive of post-depositional processes (Stein, 1983; Wood and Johnson, 1978). Using the data published in Clarkson et al. (2015) and the results of this trampling experiment we can estimate new ages for the lowest artefacts at Madjedbebe. For example, Clarkson et al. (2015) report the lowest artefacts at a depth of $2.87 \mathrm{~m}$ below the surface. Using the loess regression described above, we can compute an age of $65.2 \mathrm{ka}$ for those 
sediments. If those artefacts were actually deposited on a surface 0.1 to $0.2 \mathrm{~m}$ above that depth, we can compute ages of $64.3 \mathrm{ka}$ to $62.1 \mathrm{ka}$ for those surfaces. The error term (two standard deviations) on the nearest OSL sample to these lowest artefacts is $8.2 \mathrm{ka}$ (KTL-162), so the variation in the age of the artefacts due to trampling ( $3.1 \mathrm{ka}$ ) is less than half of the error on the OSL age. The unconsolidated nature of our trampling substrate means that our experimental artefacts may have experienced greater downward movement than what occurs to artefacts in the more compact archaeological deposits. This means our estimates here reflect a worst-case scenario for artefact displacement due to trampling. This finding does not conclusively resolve the debate about the age of the oldest artefacts at this site -- questions remain about the effects of other post-depositional processes, and the degree of mixing of the sediment grains used in the OSL analysis (Allen and O'Connell, 2014, 2003; O'Connell and Allen, 2004). However, it does help us to understand the magnitude of the effect of trampling at this site, which seems to be low, relative to uncertainties in ages produced by OSL methods.

\section{Conclusion}

541 Trampling is as an important post-depositional process that influences spatial patterning of 542 artefacts in surface and stratified deposits. Our experiment used the Zingg system of quantifying clast form to investigate the relationship between artefact size and form attributes and movement resulting from trampling. We used a trampling substrate made from the sediments of the Madjedbebe excavations to increase the relevance of our results to the debate about artefact movement in the Pleistocene deposits at Madjedbebe. Artefact elongation is a significant predictor of the horizontal distance an artefact is moved by trampling. Length, width, thickness and volume are significant predictors of the vertical distance an artefact is moved by trampling, when direction is considered. They are also predictors for changes in artefact orientation, but there are no significant predictors of artefact plunge. For overall vertical displacement, only form and flatness are significant predictors. However, the explanatory power of these artefact form and size variables is small, indicating that many other factors are also important in determining how an artefact moves during trampling. It is not possible to use artefact size and form to reliably identify artefacts in an archaeological assemblage that have been moved the most by trampling.

Our experiment is limited by the short duration of the trampling events, and the small number of events. To explore the impact of long-term trampling on archaeological deposits, we used our observed data as inputs to a simulation of a large number of trampling events. The simulation resulted in extensive horizontal movement, but only limited vertical movement, rarely more than 0.1 to $0.2 \mathrm{~m}$ below the surface. We applied the results of the simulation to the archaeological stratigraphy at Madjedbebe, a site in northern Australia with controversial evidence of early human occupation. We find that when the effects of trampling are considered, the age of the lowest artefacts in the deposit remains within the error range of the OSL ages used to date the deposit. We conclude that trampling has probably not contributed to extensive downward displacement of artefacts at Madjedbebe.

565 Future directions in experimental studies of post-depositional artefact movement might explore 566 the relationship between the body mass, foot size and gait of the person trampling. While we controlled these variables by using a single person for all the trampling, it is possible that variations in the physical attributes of the person and how they walk might be predictive of artefact displacement. A second important question is how variations in the texture of the deposit 
570 could be used to predict artefact movement. Our experiment was conducted on loose, well-sorted 571 sand, and this might result in higher values of artefact displacement compared to other types of 572 deposit. For example, highly compact deposits, shell middens, or deposits with a high percentage

573 of angular gravel might be predicted to have much smaller distances that artefacts move due to 574 trampling. The more compact sediment requires higher energy for artefacts to penetrate, and the larger clasts would act as barriers to artefact movement. By experimenting with a range of different deposit textures it may be possible to identify how much texture variation can predict

577 artefact movement due to trampling.

\section{Acknowledgements}

579 The authors are grateful to the custodians of Madjedbebe, the Mirarr Senior Traditional Owners, 580 Yvonne Margarula and May Nango, and to our research partners, the Gundjeihmi Aboriginal 581 Corporation (GAC), for granting permission to carry out this research and publish this paper. The 582 GAC have approved publication of this study. Thanks to David Vadiveloo and Justin O'Brien for 583 their support, advice and guidance at Madjedbebe. Thanks to Danny Johnson for doing the 584 walking to trample the artefacts in the experiment. We acknowledge the work of Jo Kamminga, 585 Mike Smith, Bert Roberts and the late Rhys Jones during earlier excavations at Madjedbebe. We 586 thank the Australian Research Council for funding our research through a Discovery Project 587 grant to BM, CC, RF (DPl10102864). BM was also supported by a UW-UQ Trans-Pacific 588 Fellowship and an Australian Research Council Future Fellowship (FT140100101).

589 Colophon

590 This report was generated on 2017-02-06 12:39:42 using the following computational

591 environment and dependencies:

592 \#\# Session info

$593-$

$\begin{array}{llll}594 & \# \# & \text { setting } & \text { value } \\ 595 & \# \# & \text { version } & \text { R version 3.3.2 (2016-10-31) } \\ 596 & \# \# & \text { system } & \text { x86_64, mingw32 } \\ 597 & \# \# & \text { ui } & \text { RTerm } \\ 598 & \# \# & \text { language } & \text { (EN) } \\ 599 & \# \# & \text { collate } & \text { English_Australia.1252 } \\ 600 & \# \# & \text { tz } & \text { America/Los_Angeles } \\ 601 & \# \# & \text { date } & \text { 2017-02-06 }\end{array}$

602 \#\# Packages

$603-$

\begin{tabular}{|c|c|c|c|c|c|c|}
\hline 04 & \#\# & package & * version & date & source & \\
\hline 05 & \#\# & assertthat & 0.1 & $2013-12-06$ & CRAN (R & $3.3 .2)$ \\
\hline & \#\# & backports & 1.0 .4 & $2016-10-24$ & CRAN（R & 2) \\
\hline & \#\# & bookdown & 0.3 & $2016-11-28$ & CRAN（R & 2) \\
\hline & \#\# & colorspace & $1.2-7$ & $2016-10-11$ & CRAN（R & $3.3 .2)$ \\
\hline & \#\# & DBI & $0.5-1$ & $2016-09-10$ & CRAN（R & $3.3 .2)$ \\
\hline & \#\# & devtools & 1.12 .0 & $2016-06-24$ & CRAN (R & $3.3 .2)$ \\
\hline
\end{tabular}




\begin{tabular}{|c|c|c|c|c|c|c|}
\hline 611 & \#\# & digest & & 0.6 .10 & $2016-08-02$ & CRAN ( $R \quad 3.3 .2)$ \\
\hline 612 & \#\# & dplyr & $*$ & 0.5 .0 & $2016-06-24$ & CRAN (R 3.3.2) \\
\hline 613 & \#\# & evaluate & & 0.10 & $2016-10-11$ & CRAN (R 3.3.2) \\
\hline 614 & \#\# & ggplot2 & $*$ & 2.2 .0 & 2016-11-11 & CRAN (R 3.3.2) \\
\hline 615 & \#\# & gridExtra & $*$ & 2.2 .1 & $2016-02-29$ & CRAN (R 3.3.2) \\
\hline 616 & \#\# & gtable & & 0.2 .0 & $2016-02-26$ & CRAN (R 3.3.2) \\
\hline 617 & \#\# & htmltools & & 0.3 .5 & $2016-03-21$ & CRAN (R 3.3.2) \\
\hline 618 & \#\# & knitr & * & 1.15 .1 & $2016-11-22$ & CRAN (R 3.3.2) \\
\hline 619 & \#\# & lazyeval & & 0.2 .0 .9000 & $2016-12-30$ & Github (hadley/lazyeval@c155c3d) \\
\hline 620 & \#\# & magrittr & & 1.5 & $2014-11-22$ & CRAN (R 3.3.2) \\
\hline 621 & \#\# & memoise & & 1.0 .0 & $2016-01-29$ & CRAN (R 3.3.2) \\
\hline 622 & \#\# & munsell & & 0.4 .3 & $2016-02-13$ & CRAN (R 3.3.2) \\
\hline 623 & \#\# & plyr & & 1.8 .4 & $2016-06-08$ & CRAN (R 3.3.2) \\
\hline 624 & \#\# & R6 & & 2.2 .0 & $2016-10-05$ & CRAN (R 3.3.2) \\
\hline 625 & \#\# & Rcpp & & 0.12 .8 & $2016-11-17$ & CRAN (R 3.3.2) \\
\hline 626 & \#\# & readxl & $*$ & 0.1 .1 & $2016-03-28$ & CRAN (R 3.3.2) \\
\hline 627 & \#\# & rmarkdown & & 1.3 & $2016-12-21$ & CRAN (R 3.3.2) \\
\hline 628 & \#\# & rprojroot & & 1.1 & $2016-10-29$ & CRAN (R 3.3.2) \\
\hline 629 & \#\# & scales & & 0.4 .1 & 2016-11-09 & CRAN (R 3.3.2) \\
\hline 630 & \#\# & stringi & & 1.1 .2 & $2016-10-01$ & CRAN (R 3.3.2) \\
\hline 631 & \#\# & stringr & $*$ & 1.1 .0 & $2016-08-19$ & CRAN (R 3.3.2) \\
\hline 632 & \#\# & tibble & & 1.2 & $2016-08-26$ & CRAN (R 3.3.2) \\
\hline 633 & \#\# & withr & & 1.0 .2 & $2016-06-20$ & CRAN (R 3.3.2) \\
\hline 634 & \#\# & yaml & & 2.1 .14 & $2016-11-12$ & CRAN (R 3.3.2) \\
\hline
\end{tabular}

635 The current git commit of this file is d452d3919990568e4416c4668d25ac977ed96bf1, which is 636 on the master branch and was made by Ben Marwick on 2017-01-30 10:59:48. The current 637 commit message is "version number". The repository is online at 638 https://github.com/benmarwick/mjbtramp

\section{References}

640 Aldenderfer, M., 1991. The analytical engine: Computer simulation and archaeological 641 research. Archaeological Method and Theory 3, 195-247.

642 Allen, J., O'Connell, J.F., 2014. Both half right: Updating the evidence for dating first human 643 arrivals in sahul. Australian Archaeology 86-108.

644 Allen, J., O'Connell, J.F., 2003. The long and the short of it, archaeological approaches to 645 determining when humans first colonised australia and new guinea. Australian 646 Archaeology 5-19.

647 Barrett, P., 1980. The shape of rock particles, a critical review. Sedimentology 27, 291-303.

648 Barton, R.N.E., Bergman, C.A., 1982. Hunters at hengistbury: Some evidence from 649 experimental archaeology. World Archaeology 14, 237-248.

650 doi:10.1080/00438243.1982.9979864

651 Benito-Calvo, A., Martínez-Moreno, J., Mora, R., Roy, M., Roda, X., 2011. Trampling 652 experiments at cova gran de santa linya, pre-pyrenees, spain: Their relevance for 
653 archaeological fabrics of the upper-Middle paleolithic assemblages. Journal of 654 Archaeological Science 38, 3652-3661. doi:http://dx.doi.org/10.1016/j.jas.2011.08.036

655 Benn, D.I., Ballantyne, C.K., Illenberger, W.K., 1992. Pebble shape (and size!); discussion and 656 reply. Journal of Sedimentary Research 62, 1147-1155.

657 Bird, M.I., Turney, C.S.M., Fifield, L.K., Jones, R., Ayliffe, L.K., Palmer, A., Cresswell, R., 658 Robertson, S., 2002. Radiocarbon analysis of the early archaeological site of nauwalabila i, 659 arnhem land, australia: Implications for sample suitability and stratigraphic integrity. 660 Quaternary Science Reviews 21, 1061-1075. doi:http://dx.doi.org/10.1016/S0277$6613791(01) 00058-0$

662 Blott, S.J., Pye, K., 2008. Particle shape: A review and new methods of characterization and 663 classification. Sedimentology 55, 31-63.

664 Bowdler, S., 1991. Some sort of dates at malakunanja ii: A reply to roberts et al. Australian 665 Archaeology 32, 50-51.

666 Bunn, H., John, W.K.H., Isaac, G., Kaufulu, Z., Kroll, E., Schick, K., Toth, N., Behrensmeyer, A.K., 667 1980. FxJj50: An early pleistocene site in northern kenya. World Archaeology 12, 109-136.

668 Cahen, D., Moeyersons, J., 1977. Subsurface movements of stone artefacts and their 669 implications for the prehistory of central africa. Nature 266, 812-815.

670 Chambers, J.M., 1991. Statistical models in s, 1st ed, Chapman \& hall computer science 671 series. Chapman; Hall/CRC.

672 Clarkson, C., Smith, M., Marwick, B., Fullagar, R., Wallis, L.A., Faulkner, P., Manne, T., Hayes, 673 E., Roberts, R.G., Jacobs, Z., Carah, X., Lowe, K.M., Matthews, J., Florin, S.A., 2015. The 674 archaeology, chronology and stratigraphy of madjedbebe (malakunanja ii): A site in 675 northern australia with early occupation. Journal of Human Evolution 83, 46-64.

676 doi:http://dx.doi.org/10.1016/j.jhevol.2015.03.014

677 Cook, R.D., 1979. Influential observations in linear regression. Journal of the American 678 Statistical Association 74, 169-174. doi:10.1080/01621459.1979.10481634

679 Dominguez-Solera, S., 2010. An experiment on the vertical migration of archaeological 680 materials in clay deposits. Journal of Taphonomy 8, 69-74.

681 Driscoll, K., Alcaina, J., Égüez, N., Mangado, X., Fullola, J.-M., Tejero, J.-M., 2015. Trampled 682 under foot: A quartz and chert human trampling experiment at the cova del parco rock 683 shelter, spain. Quaternary International.

684 Dryden, I.L., Mardia, K.V., 1998. Statistical shape analysis. J. Wiley Chichester.

685 Eren, M.I., Durant, A., Neudorf, C., Haslam, M., Shipton, C., Bora, J., Korisettar, R., Petraglia, 686 M., 2010. Experimental examination of animal trampling effects on artifact movement in 687 dry and water saturated substrates: A test case from south india. Journal of Archaeological 688 Science 37, 3010-3021. 
689 Faraway, J.J., 2014. Linear models with r, 2nd ed, Chapman \& hall/crc texts in statistical 690 science. Taylor \& Francis.

691 Fox, J., Weisberg, S., 2010. An r companion to applied regression. Sage.

692 Gifford-Gonzalez, D., Damrosch, D.B., Damrosch, D.R., Pryor, R.L., Johnand Thunen, 1985. 693 The third dimension in site structure: An experiment in trampling and vertical dispersal.

694 American Antiquity 50, 803-818.

695 Greenland, S., Senn, S.J., Rothman, K.J., Carlin, J.B., Poole, C., Goodman, S.N., Altman, D.G., 696 2016. Statistical tests, p values, confidence intervals, and power: A guide to

697 misinterpretations. European Journal of Epidemiology 31, 337-350. doi:10.1007/s10654-

698 016-0149-3

699 Grosman, L., Smikt, O., Smilansky, U., 2008. On the application of 3-d scanning technology 700 for the documentation and typology of lithic artifacts. Journal of Archaeological Science 35, 701 3101-3110. doi:http://dx.doi.org/10.1016/j.jas.2008.06.011

702 Hiscock, P., 1990. How old are the artefacts in malakunanja ii? Archaeology in Oceania 25, 703 122-124.

704 Hofman, J.L., 1986. Vertical movement of artifacts in alluvial and stratified deposits. Current 705 Anthropology 27, 163-171.

706

707

Kamminga, J., Allen, H., Study, A.R.R.E.F.-F., 1973. Alligator rivers environmental fact finding 708 study : Report of the archaeological survey. [Darwin : Government Printer for Alligator Rivers Region Environmental Fact-Finding Study].

Keeley, L.H., 1991. Tool use and spatial patterning, in: The Interpretation of Archaeological Spatial Patterning. Springer, pp. 257-268.

711 Kohler, T.A., 2015. Review of agent-based modeling and simulation in archaeology 712 (advances in geographic information science).

713 Lake, M.W., 2014. Trends in archaeological simulation. Journal of Archaeological Method 714 and Theory 21, 258-287.

715 Lycett, S.J., Cramon-Taubadel, N. von, Foley, R.A., 2006. A crossbeam co-ordinate caliper for

716

717

718 the morphometric analysis of lithic nuclei: A description, test and empirical examples of application. Journal of Archaeological Science 33, 847-861.

721 doi:http://dx.doi.org/10.1016/j.jas.2005.10.014

722 Moeyersons, J., 1978. The behaviour of stones and stone implements, buried in 723 consolidating and creeping kalahari sands. Earth Surface Processes 3, 115-128.

724 doi:10.1002/esp.3290030203 
725 Nielsen, A.E., 1991. Trampling the archaeological record: An experimental study. American

726 Antiquity 56, 483-503.

727 Oakey, R.J., Green, M., Carling, P.A., Lee, M.W., Sear, D.A., Warburton, J., 2005. Grain-shape 728 analysis-A new method for determining representative particle shapes for populations of 729 natural grains. Journal of Sedimentary Research 75, 1065-1073. doi:10.2110/jsr.2005.079

730 O'Connell, J.F., Allen, J., 2004. Dating the colonization of sahul (pleistocene australia-New

731 guinea): A review of recent research. Journal of Archaeological Science 31, 835-853.

732 Pewsey, A., Neuhäuser, M., Ruxton, G.D., 2013. Circular statistics in r. Oxford University

733 Press.

734 Richardson, N., 1992. Conjoin sets and stratigraphic integrity in a sandstone shelter:

735 Kenniff cave (queensland, australia). Antiquity 66, 408-418.

736 doi:10.1017/S0003598X00081540

737 Roberts, R.G., Jones, R., Smith, M.A., 1990. Thermoluminescence dating of a 50,000-year-old 738 human occupation site in northern australia. Nature 345, 153-156.

739 Roberts, R.G., Jones, R., Spooner, N.A., Head, M.J., Murray, A.S., Smith, M.A., 1994. The human 740 colonisation of australia: Optical dates of 53,000 and 60,000 years bracket human arrival at

741 deaf adder gorge, northern territory. Quaternary Science Reviews 13, 575-583.

742 Stein, J.K., 1983. Earthworm activity: A source of potential disturbance of archaeological

743 sediments. American Antiquity 48, 277-289. doi:10.2307/280451

744 Stevenson, M.G., 1991. Beyond the formation of hearth-associated artifact assemblages, in:

745 The Interpretation of Archaeological Spatial Patterning. Springer, pp. 269-299.

746 Stockton, E.D., 1973. Shaw's creek shelter: Human displacement of artefacts and its 747 significance. Mankind 9, 112-117.

748 Uthus, L., Hoff, I., Horvli, I., 2005. Evaluation of grain shape characterization methods for 749 unbound aggregates, in: Paper Proceedings. 7th International Conference on the Bearing 750 Capacity of Roads, Railways and Airfields, Trondheim Norway.

751 Villa, P., Courtin, J., 1983. The interpretation of stratified sites: A view from underground. 752 Journal of Archaeological Science 10, 267-281. doi:http://dx.doi.org/10.1016/0305-

753 4403(83)90011-0

754 Wickham, H., Cook, D., Hofmann, H., 2015. Visualizing statistical models: Removing the 755 blindfold. Statistical Analysis and Data Mining: The ASA Data Science Journal 8, 203-225. 756 doi:10.1002/sam.11271

757 Wilk, R., Schiffer, M.B., 1979. The archaeology of vacant lots in tucson, arizona. American 758 Antiquity 44, 530-536. doi:10.2307/279551

759 Wood, W.R., Johnson, D.L., 1978. A survey of disturbance processes in archaeological site 760 formation. Advances in Archaeological Method and Theory 1, 315-381. 
761 Woronow, A., Illenberger, W.K., 1992. Pebble shape (and size); discussion and reply.

762 Journal of Sedimentary Research 62, 536-540.

763 Yorston, R.M., Gaffney, V.L., Reynolds, P.J., 1990. Simulation of artefact movement due to 764 cultivation. Journal of Archaeological Science 17, 67-83.

765 Zingg, T., 1935. Beitrag zur schotteranalyse. Schweizerische Mineralogische und

766 Petrographische Mitteilungen 15, 38-140. 